\title{
Effects of nasal high flow on nocturnal hypercapnia, sleep, and sympathovagal balance in patients with neuromuscular disorders
}

\author{
Anna Christina Meyer ${ }^{1}$ Jens Spiesshoefer ${ }^{1,2,9} \cdot$ Nina Christina Siebers $^{1} \cdot$ Anna Heidbreder $^{1,3}$. \\ Christian Thiedemann ${ }^{1} \cdot$ Hartmut Schneider ${ }^{4}$. Andrew T. Braun ${ }^{5} \cdot$ Winfried Randerath $^{6,7} \cdot$ Peter Young $^{8}$. \\ Michael Dreher ${ }^{9} \cdot$ Matthias Boentert ${ }^{1,10}$ (i)
}

Received: 17 June 2020 / Revised: 24 October 2020 / Accepted: 24 November 2020 / Published online: 2 December 2020

(C) The Author(s) 2020

\begin{abstract}
Purpose In neuromuscular disorders (NMD), inspiratory muscle weakness may cause sleep-related hypoventilation requiring non-invasive ventilation (NIV). Alternatively, nasal high flow therapy (NHF) may ameliorate mild nocturnal hypercapnia (NH) through washout of anatomical dead space and generation of positive airway pressure. Ventilatory support by NIV or NHF might have favourable short-term effects on sympathovagal balance (SVB). This study comparatively investigated the effects of NHF and NIV on sleep-related breathing and SVB in NMD patients with evolving NH.

Methods Transcutaneous $\mathrm{CO}_{2}\left(\mathrm{p}_{\mathrm{tc}} \mathrm{CO}_{2}\right)$, peripheral oxygen saturation $\left(\mathrm{SpO}_{2}\right)$, sleep outcomes and SVB (spectral analysis of heart rate, diastolic blood pressure variability) along with haemodynamic measures (cardiac index, total peripheral resistance index) were evaluated overnight in 17 patients. Polysomnographies (PSG) were randomly split into equal parts with no treatment, NIV and NHF at different flow rates (20 l/min vs. 50 1/min). In-depth analysis of SVB and haemodynamics was performed on 10 min segments of stable N2 sleep taken from each intervention.

Results Compared with no treatment, NHF20 and NHF50 did not significantly change $\mathrm{p}_{\mathrm{tc}} \mathrm{CO}_{2}, \mathrm{SpO}_{2}$ or the apnea hypopnea index (AHI). NHF50 was poorly tolerated. In contrast, NIV significantly improved both gas exchange and AHI without adversely affecting sleep. During daytime, NHF20 and NHF50 had neutral effects on ventilation and oxygenation whereas NIV improved $\mathrm{p}_{\mathrm{tc}} \mathrm{CO}_{2}$ and $\mathrm{SpO}_{2}$. Effects of NIV and NHF on SVB and haemodynamics were neutral during both night and daytime.

Conclusions NHF does not correct sleep-disordered breathing in NMD patients with NH. Both NHF and NIV exert no immediate effects on SVB.
\end{abstract}

Keywords Nasal high flow therapy $\cdot$ Hypercapnia $\cdot$ Translational respiratory physiology $\cdot$ Neuromuscular disorders $\cdot$ Sympathetic drive

Anna Christina Meyer and Jens Spiesshoefer contributed equally to this work.

Matthias Boentert

matthias.boentert@ukmuenster.de

1 Department of Neurology with Institute for Translational Neurology, Münster University Hospital, Munster, Germany

2 Institute of Life Sciences, Scuola Superiore Sant'Anna, Pisa, Italy

3 Department of Neurology, Medical University of Innsbruck, Innsbruck, Austria

4 Division of Allergy, Pulmonary and Critical Care, Department of Medicine, University of Wisconsin, Madison, WI, USA
5 Sleep Disorders Center, Bayview Hospital, School of Medicine, Johns Hopkins University, Baltimore, MD, USA

6 Bethanien Hospital gGmbH Solingen, Solingen, Germany

7 Institute for Pneumology at the University of Cologne, Solingen, Germany

8 Medical Park Klinik Reithofpark, Bad Feilnbach, Germany

9 Department of Pneumology and Intensive Care Medicine, University Hospital RWTH, Aachen, Germany

10 Department of Medicine, UKM Marienhospital, Steinfurt, Germany 


\section{Introduction}

In patients with neuromuscular disorders (NMD), respiratory muscle involvement is common and a major cause of morbidity and mortality [1]. It substantially affects overall prognosis in amyotrophic lateral sclerosis (ALS) and Duchenne's muscular dystrophy (DMD) [2,3] but may also evolve in slowly progressive NMD, including hereditary myopathies such as late-onset Pompe disease (LOPD), myotonic dystrophy type 1 (DM1) and facioscapulohumeral dystrophy (FSHD) [4-9]. Pathophysiologically, respiratory muscle weakness leads to alveolar hypoventilation with hypercapnia which manifests during rapid eye movement (REM) sleep first [10]. With disease progression, hypoventilation and hypercapnia spread to non-REM sleep stages, eventually followed by daytime hypercapnia and type II respiratory failure $[1,10]$.

Non-invasive ventilation (NIV) is indicated when respiratory muscle weakness is accompanied by nocturnal hypercapnia $(\mathrm{NH})$ and sleep-related symptoms [11], but long-term data on the effects of NIV in patients with slowly progressive NMD and mild NH are scarce and conflicting. For example, treatment adherence and therapeutic benefits have been reported to be low or indefinite in patients with DM1, in particular [12]. In this population, adherence to NIV has been shown to strongly depend on sleep-related symptoms and leakage of air or other respiratory-related issues [13]. With regard to other slowly progressing myopathies, no similar evidence has been collected to date, but based on own clinical observations a subset of patients with evolving $\mathrm{NH}$ and mild or even absent sleep-related complaints have considerable problems to tolerate nocturnal NIV. In these individuals, treatment-related inconveniences due to mask intolerance, air leakage, aerophagy and patient-ventilator dyssynchrony may be perceived as more serious than subjective symptoms of sleep-disordered breathing (SDB). As long as $\mathrm{NH}$ is not severe, these patients might benefit from different ventilator settings or an alternative type of ventilatory support which is - potentially - easier to tolerate. First, spontaneous BiPAP mode (with mere inspiratory support) can be used in which no respiratory rate is specified and the risk of dyssynchrony is reduced accordingly. Second, nasal high-flow (NHF) oxygen therapy could be considered as a treatment alternative since it has previously been shown to exert beneficial effects on several aspects of ventilation and gas exchange. To date, NHF oxygen therapy has mainly been used for treatment of acute hypoxic respiratory failure where it improves pulmonary gas exchange and relieves shortness of breath [14]. But also in patients with chronic obstructive pulmonary disease (COPD) and hypercapnic respiratory failure, NHF oxygen therapy has been reported to enhance oxygenation and reduce both respiratory rate and hypercapnia [14-17]. Using special nasal prongs NHF supplies warm humidified air with a high flow rate. Apart from an increase of inspiratory oxygen concentration (if $\mathrm{O}_{2}$ is supplemented), NHF is thought to generate flow-dependent positive airway pressure and reduce dead-space ventilation and $\mathrm{CO}_{2}$ rebreathing from the nasopharynx and trachea [18-21]. Only one case report has been published on the use of NHF in a patient with acute respiratory failure of neuromuscular origin [22], and no evidence is available with regard to NMD patients with mere $\mathrm{NH}$ or chronic hypercapnic respiratory failure. Assuming that alveolar ventilation corresponds to tidal volume minus dead-space ventilation, improvement of $\mathrm{CO}_{2}$ elimination can potentially be achieved by NHF in NMD patients with evolving NH.

At the same time, it can be hypothesised that alleviation of SDB beneficially impacts autonomic nervous system function or sympathovagal balance (SVB), respectively. This is based on the assumption that hypoventilation is associated with an increased sympathetic drive which is supported by a small number of experimental studies [23, 24]. Notably, an increase in respiratory rate may be related not only to diaphragm weakness and hypercapnia but also to increased sympathetic drive.

Therefore, the present study investigated the effects of NHF (without additional oxygen supplementation) on gas exchange, sleep and SVB in patients with NMD and mild to moderate $\mathrm{NH}$. The effects of different flow rates $(20 \mathrm{l} / \mathrm{min}-\mathrm{NHF} 20$ - vs. $50 \mathrm{l} /$ min-NHF50) were compared with no treatment and NIV therapy. In addition, immediate effects of NHF20, NHF50 and NIV on SVB during the awake state at daytime were also assessed.

\section{Methods}

\section{Study participants}

Adult patients with NH due to genetically proven NMD were consecutively recruited from our academic sleep laboratory from April 2018 to August 2019. Inclusion criteria comprised ongoing NIV for less than 5 years, NIV use only during nocturnal sleep and no vital dependence on NIV. Diagnosis of NH and NIV had to be established in our own institution before in order to warrant reliability of clinical and baseline respiratory data. The study protocol conformed to the 1975 Declaration of Helsinki and was approved by the local authorities (Ethikkommission der Ärztekammer Westfalen Lippe und der Medizinischen Fakultät der Westfälischen Wilhelms-Universität Münster; Az. 2017-668-f-S). All subjects gave written informed consent to participate in the study. The project was registered under the German Clinical Trials Registry (drks.de Identifier: DRKS00013903 and DRKS00013905).

In all participants, diagnosis of $\mathrm{NH}$ had previously been established using transcutaneous capnometry (Sentec, Therwil, Switzerland), based on a peak carbon dioxide tension $\left(\mathrm{p}_{\mathrm{tc}} \mathrm{CO}_{2}\right) \geq 50 \mathrm{mmHg}$ or an increase in $\mathrm{p}_{\mathrm{tc}} \mathrm{CO}_{2}$ by $10 \mathrm{mmHg}$ above the awake baseline value $[11,25]$. 


\section{Assessments}

All subjects underwent detailed neurological assessment of motor abilities for documentation of their individual functional status. Spirometric and manometric measurements (forced vital capacity/FVC, maximum inspiratory pressure/MIP) were also included in the data set, if performed less than 6 months prior to study participation.

\section{Sleep studies}

During the first night in the sleep laboratory, participants underwent both full polysomnography (PSG, Nihon Kohden, Rosbach, Germany) and transcutaneous capnometry. For the first half of the night (22:00 pm-02:00 am), patients did not use NIV in order to allow confirmation of NH. During the second half of the night (02:00-06:00 am), patients applied their own NIV device, and optimal ventilator settings were verified by confirming normocapnia $\left(\mathrm{p}_{\mathrm{tc}} \mathrm{CO}_{2}<\right.$ $50 \mathrm{mmHg}$ ), normoxia $\left(\mathrm{SpO}_{2}<90 \%\right.$ for less than $\left.5 \mathrm{~min}\right)$ and an apnea hypopnea index (AHI) below 5 per hour. Validation of respiratory and sleep parameters were conducted according to standard diagnostic guidelines [26]. If necessary, ventilator settings were modified in order to achieve both normal gas exchange and AHI. During the second night, PSG was randomly divided into equal parts of about 2-h duration each with no treatment, NIV (using the previous night's settings), NHF20 and NHF50. Prior to the second night, each subject was familiarised with both the NHF device and the noninvasive haemodynamic and SVB monitoring system.

\section{Non-invasive haemodynamic and SVB monitoring}

SVB and haemodynamics were monitored using the Task Force Monitor ${ }^{\circledR}$ system (TFM®, CNSystems, Graz, Austria) which has previously been validated [27-31]. For assessment of SVB, diastolic blood pressure variability (dBPV) and heart rate variability (HRV) were analysed using the continuous noninvasive arterial blood pressure signal (CNAP® Technology, CNSystems, Graz, Austria; sampling rate $100 \mathrm{~Hz}$ ) and a 3-lead electrocardiogram (sampling rate $1000 \mathrm{~Hz}$ ), both implemented in the TFM®. Both HRV (based on continuous recording of variability in RR intervals) and $\mathrm{dBPV}$ were initially expressed in $\mathrm{ms}^{2}$ but were then normalised for total power spectra with the unit being percent. Data were computed by frequency domain analysis (adaptive autoregressive parameter AAR model) and presented as the high-frequency component (HF; 0.15$0.40 \mathrm{~Hz}$ ), low-frequency component (LF; $0.04-0.15 \mathrm{~Hz}$ ) and their relative ratio $(\mathrm{LF} / \mathrm{HF})$ for both $\mathrm{HRV}$ and $\mathrm{dBPV}$. A higher $\mathrm{LF} / \mathrm{HF}$ ratio indicates increased sympathetic drive as the LF component (of dBPV variability in particular) is believed to reflect sympathetic activation, and the HF component (of both
$\mathrm{HRV}$ and $\mathrm{dBPV}$ ) is considered to reflect parasympathetic drive [27-31].

Baroreceptor reflex sensitivity (BRS) was measured using the sequence method. The time constant of this stimulusresponse relationship primarily reflects vagal but not sympathetic responsiveness (particularly with respect to the up sequences) [32].

Haemodynamic measurements included beat-to-beat systolic and diastolic blood pressure; these were continuously recorded and validated against periodic measurements obtained every $15 \mathrm{~min}$ by oscillometric recording from the upper contralateral arm. Transthoracic impedance measurements were used to estimate cardiac stroke volume index, cardiac index and systemic vascular resistance, from which the total peripheral resistance index was calculated (mean blood pressure divided by cardiac index). Bioimpedance-based measurements have been previously validated against invasive haemodynamic monitoring in the catheter lab [27-31].

All signals were simultaneously acquired and displayed in real time on a personal computer running DOMINO 2.9.0 software.

\section{In-depth analysis of SVB and haemodynamics at night}

As measurements were fully attended (A.M. and J.S.), it was possible to evaluate sleep stages, respiration and both haemodynamic and SVB on-line and on a "beat to beat" basis. From each patient, four sleep segments were chosen by visual identification, each of them $10 \mathrm{~min}$ in duration. Each segment had to be characterised by stable N2 sleep and sinus rhythm with less than $5 \%$ ectopic beats in order in order to enable valid analysis of HRV, dBPV and BRS). Sleep segments were selected from each of the four interventions (no treatment, NIV, NHF20 and NHF50).

\section{Daytime measurements}

After resting for $1 \mathrm{~h}$ in the half-supine position baseline values were obtained for $\mathrm{p}_{\mathrm{tc}} \mathrm{CO}_{2}, \mathrm{SpO}_{2}$, haemodynamic and SVB measures. Thereafter, patients were exposed to NHF20, NHF50 and NIV in a randomised order. Each intervention lasted for $10 \mathrm{~min}$. Interventions were separated by periods of spontaneous breathing of 3-min minimum until heart rate, blood pressure, $\mathrm{p}_{\mathrm{tc}} \mathrm{CO}_{2}$ and $\mathrm{SpO}_{2}$ had returned to baseline. At baseline and following each intervention, the patients were asked to judge their subjective wellbeing on a numerical analogue scale ranging from 0 to 10 , with " 0 " reflecting the worst and " 10 " indicating the best possible subjective wellbeing.

\section{Statistical analysis}

All analyses were performed using IBM SPSS $®$ software v. 25 (IBM Deutschland GmbH, Ehningen, Germany). Assuming a two-sided significance level of 0.05 (alpha) and $80 \%$ power 
(beta), a sample size of 15 patients in total was calculated for detection of a 2-mmHg change in $\mathrm{p}_{\mathrm{tc}} \mathrm{CO}_{2}$ (which was considered to have potential clinical relevance). Mean values and standard deviations of $\mathrm{p}_{\mathrm{tc}} \mathrm{CO}_{2}$ were derived from own preliminary data. Results were expressed as mean and standard deviation for continuous variables with a rather normal distribution, and median and interquartile range for continuous variables with a rather skewed distribution. Categorical variables were expressed as percentages, unless otherwise specified. Respiratory parameters, SVB and haemodynamic parameters derived during the different interventions were compared with baseline parameters ("no treatment" intervention) using a paired $t$ test or Wilcoxon ranksum test, as appropriate. Comparisons between values derived from all four interventions were performed using the KruskalWallis test for non-parametric data or univariate analysis of variance (ANOVA) for normally distributed values. For all tests, a $p$ value $\leq 0.05$ was considered statistically significant. For significant $p$ values, Bonferroni's post hoc correction for multiple comparisons was applied.

\section{Results}

A total of 17 patients were enrolled in the study. Table 1 summarises demographic and clinical characteristics of the study population. Neuromuscular disease entities comprised DM1 $(n=7)$, LOPD $(n=2)$, FSHD $(n=2)$, limb-girdle

Table 1 Demographic and baseline characteristics of the study population

\begin{tabular}{ll}
\hline & NMD patients $(n=17)$ \\
\hline Male, $n(\%)$ & $10(58.8)$ \\
Age, years & $47.3 \pm 14.4$ \\
BMI, $\mathrm{kg} / \mathrm{m}^{2}$ & $24.8 \pm 6.1$ \\
$\mathrm{BSA}, \mathrm{m}^{2}$ & $1.9 \pm 0.3$ \\
$\mathrm{FVC}(\%$ of normal value) & $61.6 \pm 24.4$ \\
MEP $(\%$ of reference value) & $47.6 \pm 15.2$ \\
MIP $(\%$ of reference value) & $47.7 \pm 23.0$ \\
Peak cough flow (l/min) & $246.7 \pm 101.0$ \\
AHI $/ \mathrm{h}$ & $10.6 \pm 8.3$ \\
$t<90 \%($ min $)$ & $12.7(3.9-70.2)$ \\
Min $\mathrm{SpO}_{2}$ & $80.4 \pm 10.5$ \\
Mean $\mathrm{SpO}_{2}$ & $91.4 \pm 4.5$ \\
Mean $\mathrm{p}_{\mathrm{tc}} \mathrm{CO}_{2}$ & $47.5 \pm 3.7$ \\
Peak $\mathrm{ptcO}_{2}$ & $53.4 \pm 4.0$ \\
\hline
\end{tabular}

Values are expressed as mean and standard deviation, median (interquartile range) or number of patients (\%)

$B M I$ body mass index, $B S A$ body surface area, $F V C$ forced vital capacity, $M E P$ maximal expiratory pressure, $M I P$ maximal inspiratory pressure, $A H I$ apnoea hypopnoea index, $\mathrm{SpO}_{2}$ peripheral oxygen saturation, $p_{t c} \mathrm{CO}_{2}$ transcutaneous carbon dioxide muscular dystrophy $(n=1)$, congenital myasthenic syndrome $(n=1)$, mitochondrial myopathy $(n=1)$, amyotrophic lateral sclerosis with slow disease progression $(n=1)$ and spinal and bulbar muscular atrophy $(n=1)$. One patient (male, 35 years of age) carried pathogenic mutations for both FSHD and DM1. Following daytime testing 16 out of 17 NMD patients participated in nocturnal assessment of NHF and NIV effects. Consistent with the previous diagnosis of $\mathrm{NH}$, mean and peak $\mathrm{p}_{\mathrm{tc}} \mathrm{CO}_{2}$ were increased without NIV during night 1 (Table 1). During the same night and without NIV, 4 (25.0\%) patients showed moderate or severe obstructive sleep apnea as reflected by an AHI $>15 / \mathrm{h}$. Using NIV, 6 out of 16 patients (37.5\%) showed normocapnia and normalization of the AHI throughout the intervention. In the remaining subjects, either pressure settings or minute volume had to be titrated in order to correct mild residual NH or sleep apnea, respectively.

\section{Impact of NHF20 on sleep, ventilation and sympathovagal balance (night 2)}

Objective sleep outcomes are depicted in Table 2 showing no statistical differences between the various interventions. Compared with no treatment, NHF20 did not lead to significant improvement of $\mathrm{p}_{\mathrm{tc}} \mathrm{CO}_{2}$ and AHI (Table 3). Effects of NHF20 on SVB and haemodynamic measures during N2 sleep were neutral compared with no treatment (Table 4).

\section{Impact of NHF50 on sleep, ventilation and sympathovagal balance (night 2)}

In a substantial number of participants, NHF50 was poorly tolerated with 5 out 16 NMD patients eventually declining treatment and 4 patients not showing consecutive 10 min of stable N2 sleep (Table 2). Mean duration of NHF50 usage was significantly lower than with NHF20 or NIV, and compared with no treatment, percentage of $\mathrm{N} 3$ and REM sleep was reduced (Table 2). During the NHF50 intervention peak $\mathrm{p}_{\mathrm{tc}} \mathrm{CO}_{2}$ was lower than with no treatment in the few patients tolerating the intervention (Table 3). Effects on SVB during N2 sleep were neutral compared with the no-treatment period (Table 4). Haemodynamic effects were also neutral (Table 4).

\section{Impact of NIV on sleep, ventilation and sympathovagal balance (night 2)}

Non-invasive ventilation improved nocturnal hypercapnia as reflected by a significant decrease of mean and maximum $\mathrm{p}_{\mathrm{tc}} \mathrm{CO}_{2}$ when compared with the "no treatment" period (Table 3; Cohen's d 1.35 and 1.06, respectively).. Compared with "no treatment", the percentage of REM sleep was higher during the NHF20 and NIV interventions but post hoc tests were not significant (Table 2). Since a subset of patients early requested cessation of NHF50 and continued with NIV, overall duration 


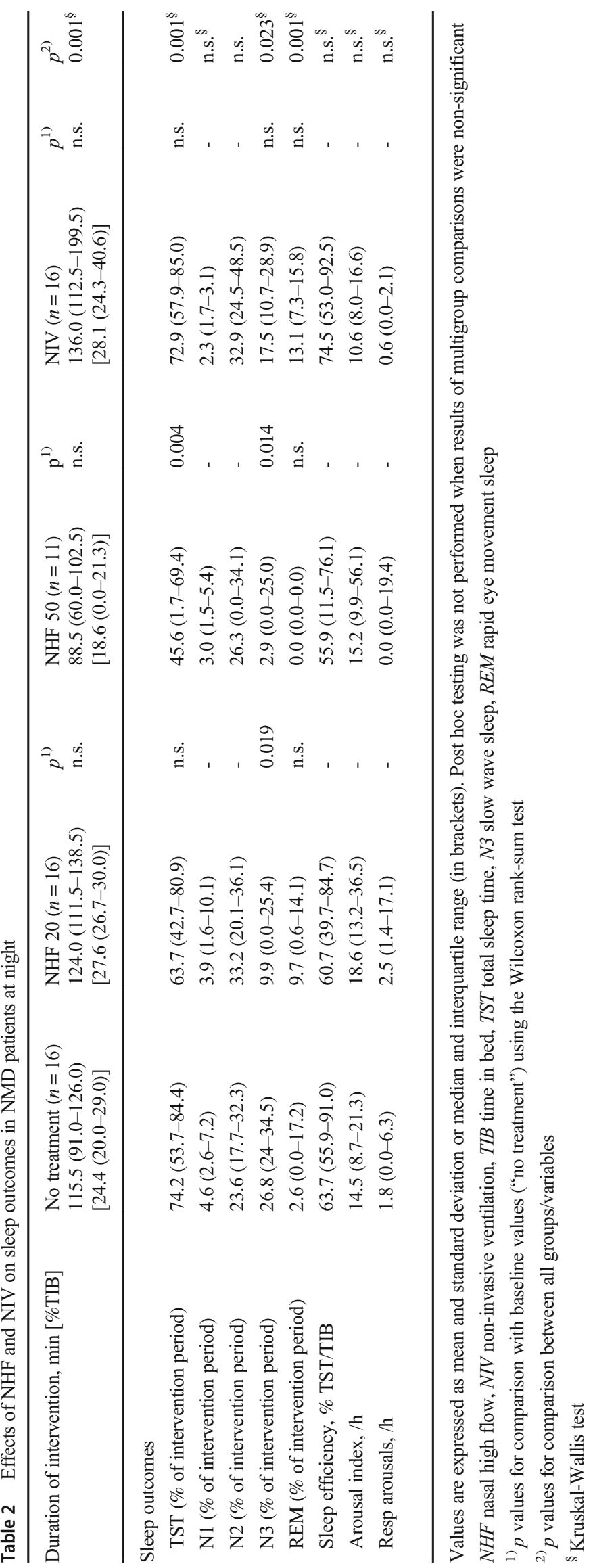


Table 3 Effects of NHF and NIV on respiratory outcomes in NMD patients at night

\begin{tabular}{|c|c|c|c|c|c|c|c|c|}
\hline & No treatment $(n=16)$ & NHF $20(n=16)$ & $p^{1)}$ & NHF $50(n=11)$ & $p^{1)}$ & $\operatorname{NIV}(n=16)$ & $p^{1)}$ & $p^{2)}$ \\
\hline AHI, /h & $9.5(0.7-16.5)$ & $6.8(2.5-31.2)$ & - & $20.7(1.1-28.9)$ & - & $2.3(0.0-3.9)$ & - & n.s. ${ }^{\S}$ \\
\hline $\mathrm{AI}, / \mathrm{h}$ & $1.2(0.0-13.8)$ & $4.0(0.4-21.3)$ & - & $19.3(1.1-28.9)$ & - & $0.2(0.0-3.1)$ & - & n.s. ${ }^{\S}$ \\
\hline $\mathrm{cAI}, / \mathrm{h}$ & $0.0(0.0-0.8)$ & $0.3(0.0-6.9)$ & - & $1.2(0.0-13.9)$ & - & $0.0(0.0-0.9)$ & - & n.s..$^{\S}$ \\
\hline $\mathrm{oAI}, / \mathrm{h}$ & $0.0(0.0-5.4)$ & $1.0(0.0-8.0)$ & - & $0.9(0.0-7.3)$ & - & $0.0(0.0-0.0)$ & - & n.s..$^{\S}$ \\
\hline $\mathrm{HI}, / \mathrm{h}$ & $0.9(0.0-6.5)$ & $2.2(0.4-5.4)$ & - & $0.0(0.0-0.6)$ & - & $0.2(0.0-1.5)$ & - & n.s. ${ }^{\S}$ \\
\hline $\mathrm{ODI}, / \mathrm{h}$ & $5.5(0.7-13.0)$ & $2.7(0.8-21.2)$ & - & $0.9(0.0-25.4)$ & - & $1.0(0.0-1.6)$ & - & n.s. ${ }^{\S}$ \\
\hline Mean $\mathrm{SpO}_{2}(\%)$ & $94.1 \pm 2.8$ & $94.1 \pm 4.0$ & - & $94.3 \pm 3.9$ & - & $95.6 \pm 2.5$ & - & n.s. ${ }^{\&}$ \\
\hline Minimum $\mathrm{SpO}_{2}, \%$ & $86.2 \pm 6.9$ & $85.9 \pm 11.2$ & - & $86.1 \pm 11.4$ & - & $84.6 \pm 11.2$ & - & n.s. ${ }^{\&}$ \\
\hline$t<90 \%, \min$ & $1.6(0.0-17.0)$ & $1.1(0.0-5.9)$ & - & $0.4(0.0-17.2)$ & - & $0.3(0.0-3.5)$ & - & n.s. ${ }^{\S}$ \\
\hline Mean $\mathrm{p}_{\mathrm{tc}} \mathrm{CO}_{2}, \mathrm{mmHg}$ & $45.5 \pm 4.7$ & $44.9 \pm 4.2$ & n.s. & $43.1 \pm 6.5$ & n.s. & $39.9 \pm 3.5$ & 0.007 & $0.063^{\&}$ \\
\hline Peak $\mathrm{p}_{\mathrm{tc}} \mathrm{CO}_{2}, \mathrm{mmHg}$ & $50.1 \pm 6.6$ & $50.1 \pm 7.9$ & n.s & $46.4 \pm 6.6$ & n.s. & $44.8 \pm 2.6$ & 0.001 & $0.009^{\&}$ \\
\hline
\end{tabular}

Values are based on the actual duration of each intervention (no treatment, NHF20, NHF50, NIV). Values are expressed as mean and standard deviation or median and interquartile range (in brackets). Post hoc tests were not performed when results of multigroup comparisons were non-significant. As an exception, the $p$ value is reported for the post hoc $t$ test comparing mean $\mathrm{p}_{\mathrm{tc}} \mathrm{CO}_{2}$ between the NIV and "no treatment" period

$N H F$ nasal high flow, $N I V$ non-invasive ventilation, $A H I$ apnoea-hypopnea index, $A I$ apnoea index, $c A I$ central apnea index, $o A I$ obstructive apnoea index, $\mathrm{HI}$ hypopnea index, $\mathrm{ODI}$ oxygen desaturation index, $\mathrm{SpO}_{2}$ peripheral oxygen saturation, $t<90 \%$ duration of oxygen desaturation $\geq 3 \%, p_{t c} \mathrm{CO}_{2}$ transcutaneous carbon dioxide tension

${ }^{1)} p$ values for comparison with baseline values ("no treatment") using either the paired $t$ test or the Wilcoxon rank-sum test as appropriate

${ }^{2)} p$ value for comparison between all groups/variables

${ }^{\S}$ Kruskal-Wallis test

\& Univariate ANOVA

of NIV usage was longer than with NHF interventions (Table 2). Different from both NHF interventions, NIV improved mean and maximum $\mathrm{p}_{\mathrm{tc}} \mathrm{CO}_{2}$ (Table 3). Effects of NIV on haemodynamics and sympathovagal balance were all neutral (Table 4).

\section{Immediate effects of NHF20, NHF50 and NIV on respiration and sympathovagal balance at daytime}

In the awake state during daytime, NHF20 and NHF50 led to a significant and flow-dependent decrease in subjective well-being (Table 5). At the same time, the effect of NHF20 and NHF50 on $\mathrm{p}_{\mathrm{tc}} \mathrm{CO}_{2}$ was neutral. Again NIV showed favourable effects on respiration as reflected by a significant decrease of $\mathrm{p}_{\mathrm{tc}} \mathrm{CO}_{2}$ (Table 5). Haemodynamic effects were neutral (Table 5).

\section{Discussion}

This is the first study which explores the effects of NHF on SDB and sleep in adult patients with slowly progressing NMD and isolated NH. Specifically, it evaluates whether NHF improves $\mathrm{CO}_{2}$ elimination and upper airway patency depending on the flow rate applied. Finally, this study assessed tolerability of nocturnal NHF and its effects on SVB during N2 sleep as compared with NIV.

From a practical point of view, this study aimed to evaluate whether or not NHF can be considered a therapeutic option for
NMD patients with evolving NH who do not tolerate NIV or who use NIV during nocturnal sleep but seek for a different kind of ventilatory support for intermittent daytime use.

The main findings of this study can be summarised as follows:

(i) Independent on the flow rate applied, NHF does not improve SDB in patients with NMD. Both alveolar hypoventilation during sleep and obstructive sleep apnea (if present) are not sufficiently treated by application of NHF. In contrast, NIV proved to successfully normalise $\mathrm{NH}$ and sleep apnea.

(ii) Nasal high flow therapy at $20 \mathrm{l} / \mathrm{min}$, and at $50 \mathrm{l} / \mathrm{min}$ in particular, is poorly tolerated and disrupts sleep whereas NIV proves to enhance objective sleep quality along with effective treatment of SDB.

(iii) Effects of NHF and NIV on autonomous nervous system activity are mainly neutral during sleep and in the awake state. Both interventions do not cause a measurable increase of sympathetic drive.

\section{Impact of NHF on sleep-related breathing}

The fact that NHF does not exert beneficial effects on sleeprelated breathing in patients with NMD suggests that mechanistic explanations for the improvement of gas exchange and 
Table 4 Effect of NHF and NIV on sympathovagal balance and haemodynamics during stable N2 sleep in NMD patients

\begin{tabular}{|c|c|c|c|c|c|c|c|c|}
\hline & No treatment $(n=16)$ & NHF $20(n=16)$ & $p^{1)}$ & NHF $50(n=7)$ & $p^{1)}$ & $\operatorname{NIV}(n=14)$ & $p^{1)}$ & $p^{2)}$ \\
\hline \multicolumn{9}{|l|}{ Sympathovagal balance } \\
\hline HFnuRRI, \% & $44.8 \pm 20.4$ & $48.3 \pm 21.7$ & - & $43.7 \pm 18.9$ & - & $44.2 \pm 22.3$ & - & n.s. ${ }^{\&}$ \\
\hline LFnuRRI, \% & $55.2 \pm 20.4$ & $51.7 \pm 21.7$ & - & $56.3 \pm 18.9$ & - & $55.8 \pm 22.3$ & - & n.s. ${ }^{\&}$ \\
\hline LF/HF RRI & $1.1(0.9-3.2)$ & $1.3(0.7-2.6)$ & - & $1.3(1.2-2.1)$ & - & $1.6(1.0-2.5)$ & - & n.s. ${ }^{\&}$ \\
\hline HFnudBPV, $\%$ & $15.3 \pm 6.8$ & $13.5 \pm 6.7$ & - & $14.3 \pm 6.4$ & - & $11.2 \pm 7.5$ & - & n.s. ${ }^{\&}$ \\
\hline LFnudBPV, \% & $45.3 \pm 10.0$ & $46.3 \pm 11.7$ & - & $40.9 \pm 15.8$ & - & $43.5 \pm 12.1$ & - & n.s. ${ }^{\&}$ \\
\hline $\mathrm{LF} / \mathrm{HF} \mathrm{dBPV}$ & $3.4(1.7-5.0)$ & $4.0(2.2-5.8)$ & - & $2.5(1.8-4.2)$ & - & $4.4(2.7-7.3)$ & - & n.s. ${ }^{\&}$ \\
\hline \multicolumn{9}{|l|}{ BRS slope } \\
\hline Up event counts & $11.5 \pm 8.5$ & $13.1 \pm 7.6$ & - & $17.3 \pm 8.3$ & - & $11.5 \pm 7.6$ & - & n.s. ${ }^{\&}$ \\
\hline Up events, $\mathrm{ms} / \mathrm{mmHg}$ & $14.8 \pm 8.4$ & $20.7 \pm 14.7$ & - & $27.0 \pm 14.5$ & - & $14.8 \pm 14.1$ & - & n.s. ${ }^{\&}$ \\
\hline Down event counts & $17.9 \pm 12.9$ & $20.3 \pm 13.4$ & - & $26.0 \pm 9.8$ & - & $11.6 \pm 7.9$ & - & n.s. ${ }^{\&}$ \\
\hline Down events, $\mathrm{ms} / \mathrm{mmHg}$ & $15.5 \pm 10.81$ & $23.5 \pm 22.4(10.3-24.8)$ & - & $29.4 \pm 18.5$ & - & $16.4 \pm 24.2$ & - & n.s. ${ }^{\&}$ \\
\hline \multicolumn{9}{|l|}{ Haemodynamic parameters } \\
\hline Heart rate, $\min ^{-1}$ & $63.6 \pm 10.5$ & $62.9 \pm 8.5$ & - & $57.9 \pm 17.1$ & - & $61.2 \pm 7.5$ & - & n.s. ${ }^{\&}$ \\
\hline Systolic BP, mmHg & $102.3 \pm 19.7$ & $102.3 \pm 17.2$ & - & $97.2 \pm 21.2$ & - & $100.7 \pm 21.4$ & - & n.s. ${ }^{\&}$ \\
\hline Diastolic BP, mmHg & $65.9 \pm 16.4$ & $65.5 \pm 14.0$ & - & $60.9 \pm 12.5$ & - & $61.9 \pm 17.5$ & - & n.s. ${ }^{\&}$ \\
\hline Stroke volume index, $\mathrm{ml} / \mathrm{beat} / \mathrm{m}^{2} \mathrm{~L} / \mathrm{m}^{2}$ & $33.5 \pm 10.0$ & $32.5 \pm 8.7$ & - & $32.6 \pm 8.5$ & - & $33.4 \pm 10.1$ & - & n.s. ${ }^{\S}$ \\
\hline Cardiac index, $\mathrm{L} / \mathrm{min} / \mathrm{m}^{2}$ & $2.1 \pm 0.6$ & $2.1 \pm 0.6$ & - & $1.9 \pm 0.3$ & - & $2.0 \pm 0.4$ & - & n.s. ${ }^{\S}$ \\
\hline TPRI, dyne $\cdot \mathrm{s} \mathrm{m}^{2} \mathrm{~cm}^{-5}$ & $3253.9 \pm 1259.0$ & $3363.2 \pm 1165.0$ & - & $3155.4 .8 \pm 862.6$ & - & $3274.7 \pm 1243.2$ & - & n.s. ${ }^{\S}$ \\
\hline
\end{tabular}

Values are expressed as mean and standard deviation or median and interquartile range (in brackets) for sleep segments of 10-min duration taken from stable N2 sleep with sinus rhythm. Post hoc tests were not performed when results of multigroup comparisons were non-significant. Analysis of BRS data is based on $9 / 12$ patients for up events and 10/12 patients for down events, respectively

$N H F$ nasal high flow, NIV non-invasive ventilation, BRS baroreceptor reflex sensitivity (up events and down events), $H F n u d B P V$ high-frequency component of diastolic blood pressure variability, $H F n u R R I$ high-frequency component of heart rate variability, $L F n u d B P V$ low-frequency component of diastolic blood pressure variability, $L F / H F d B P V$ relative ratio of low frequency and high frequency component of diastolic blood pressure variability, $L F n u R R I$ low-frequency component of heart rate variability, $L F / H F R R I$ relative ratio of low-frequency and high-frequency component of heart rate variability, n.s. not statistically significant, TPRI total peripheral resistance index

1) $p$ values for comparison with baseline values ("no treatment") using either the paired $t$ test or the Wilcoxon rank-sum test as appropriate

${ }^{2)} p$ value for comparison between all groups/variables

${ }^{\S}$ Kruskal-Wallis test

${ }^{\&}$ Univariate ANOVA

upper airway stability by NHF cannot be proven in this subgroup. First, NHF apparently does not build up sufficient positive airway pressure to sufficiently stabilise the upper airway and to substantially reduce obstructive events. This finding is consistent with previous studies that showed that every 101 of increase in NHF flow rate translate into a $\sim 1 \mathrm{cmH}_{2} \mathrm{O}$ increase in positive airway pressure [19]. Second, the assumed reduction of dead-space ventilation due to NHF did not lead to a measurable improvement of $\mathrm{CO}_{2}$ elimination. Previous studies have shown that NHF slows down respiratory rate and reduces dead-space ventilation, tidal volume and minute ventilation in healthy subjects during sleep [33]. With regard to patients, reduction of respiratory rate appears to be the most ostensible effect of NHF in adults and children [34, 35]. However, data on the effect of NHF on $\mathrm{CO}_{2}$ tension are still conflicting. Continuous use of NHF (30 1/min flow rate) for $8 \mathrm{~h}$ has been shown to significantly lower capillary $\mathrm{pCO}_{2}$ in awake patients with COPD by $0.69 \pm 0.2 \mathrm{kPa}$ or $5.18 \pm$ $1.5 \mathrm{mmHg}$, respectively [34]. In contrast, transcutaneously measured tissue $\mathrm{CO}_{2}$ did not fall after 10 min of NHF20 despite significant reduction of dead space [21]. Taking into account that NHF builds up only little positive airway pressure $\left(\sim 2 \mathrm{cmH}_{2} \mathrm{O}\right.$ with NHF20 and $\sim 5 \mathrm{cmH}_{2} \mathrm{O}$ with NHF50) that, in addition, remains stable throughout the respiratory cycle - it seems plausible that NHF could not correct NH in this study. It should be acknowledged that NHF50 appeared to improve exhalation of $\mathrm{CO}_{2}$ in those few NMD patients who did tolerate the intervention. However, differences did not reach significance most likely due to the small sample size.

In summary, the mechanistic effects of NHF appear to be insufficient to improve upper airway patency and $\mathrm{CO}_{2}$ exhalation in patients with NMD. In this context, it has to be considered as a major methodological aspect that the present study did not apply nasal high flow oxygen therapy but NHF 
Table 5 Effect of NHF20 and NHF50 on sympatho-vagal balance and haemodynamic parameters in awake NMD patients during daytime

\begin{tabular}{|c|c|c|c|c|c|c|c|c|}
\hline & Baseline & NHF 20 & $p^{1)}$ & NHF 50 & $p^{1)}$ & NIV & $p^{1)}$ & $p^{2)}$ \\
\hline Well-being score $(10-0)$ & $8.1 \pm 1.7$ & $6.2 \pm 2.4$ & 0.01 & $4.6 \pm 3.0$ & $<0.01$ & $7.6 \pm 1.6$ & 0.33 & $0.01^{\&}$ \\
\hline \multicolumn{9}{|l|}{ Respiratory parameters } \\
\hline Mean $\mathrm{SpO}_{2}, \%$ & $95.0 \pm 2.4$ & $94.4 \pm 2.5$ & - & $94.4 \pm 3.4$ & - & $96.3 \pm 1.4$ & - & n.s. ${ }^{\&}$ \\
\hline Mean $\mathrm{p}_{\mathrm{tc}} \mathrm{CO}_{2}, \mathrm{mmHg}$ & $42.1 \pm 4.4$ & $41.9 \pm 4.8$ & n.s. & $42.5 \pm 5.4$ & n.s. & $37.7 \pm 3.4$ & 0.013 & $0.026^{\&}$ \\
\hline \multicolumn{9}{|c|}{ Sympatho-vagal balance parameters } \\
\hline HFnuRRI, \% & $44.9 \pm 12.6$ & $46.2 \pm 15.8$ & - & $45.9 \pm 17.8$ & - & $44.2 \pm 15.7$ & - & n.s. ${ }^{\&}$ \\
\hline LFnuRRI, \% & $55.1 \pm 12.6$ & $53.8 \pm 15.8$ & - & $54.1 \pm 17.8$ & - & $55.8 \pm 15.7$ & - & n.s. ${ }^{\&}$ \\
\hline LF/HF RRI & $1.6 \pm 0.9$ & $1.8 \pm 1.5$ & - & $1.9 \pm 1.6$ & - & $1.8 \pm 1.1$ & - & n.s. ${ }^{\&}$ \\
\hline HFnu dBPV, $\%$ & $20.0 \pm 12.3$ & $18.1 \pm 7.6$ & - & $16.8 \pm 6.4$ & - & $19.8 \pm 8.2$ & - & n.s. ${ }^{\&}$ \\
\hline LF nudBPV, \% & $41.4 \pm 12.8$ & $42.2 \pm 10.7$ & - & $43.1 \pm 10.1$ & - & $41.8 \pm 11.0$ & - & n.s. ${ }^{\&}$ \\
\hline LF/HF dBPV & $3.3 \pm 3.0$ & $3.2 \pm 2.9$ & - & $3.4 \pm 2.6$ & - & $2.6 \pm 1.5$ & - & n.s. ${ }^{\&}$ \\
\hline \multicolumn{9}{|l|}{ BRS slope } \\
\hline Up event count, $\mathrm{n}^{\wedge}$ & $13.6 \pm 10.9$ & $15.1 \pm 10.3$ & - & $17.0 \pm 12.1$ & - & $10.2 \pm 8.5$ & - & n.s. ${ }^{\&}$ \\
\hline Up event count, $\mathrm{n}^{\wedge}$ & $13.6 \pm 10.9$ & $15.1 \pm 10.3$ & & $17.0 \pm 12.1$ & & $10.2 \pm 8.5$ & & \\
\hline Up events, $\mathrm{ms} / \mathrm{mmHg}$ & $13.8 \pm 8.1$ & $19.8 \pm 13.1$ & - & $19.4 \pm 17.3$ & - & $17.0 \pm 18.6$ & - & n.s. ${ }^{\&}$ \\
\hline Down event count, $n^{\wedge}$ & $14.4 \pm 10.5$ & $18.8 \pm 14.6$ & - & $17.9 \pm 9.7$ & - & $13.3 \pm 10.8$ & - & n.s. ${ }^{\&}$ \\
\hline Down events, $\mathrm{ms} / \mathrm{mmHg}$ & $15.1 \pm 7.6$ & $17.6 \pm 10.2$ & - & $18.9 \pm 14.9$ & - & $17.6 \pm 13.4$ & - & n.s. ${ }^{\&}$ \\
\hline \multicolumn{9}{|l|}{ Haemodynamic parameters } \\
\hline Heart rate, $\min ^{-1}$ & $70.2 \pm 9.0$ & $66.4 \pm 8.2$ & - & $65.7 \pm 9.6$ & - & $65.8 \pm 8.8$ & - & n.s. ${ }^{\&}$ \\
\hline Systolic BP, mmHg & $115.4 \pm 12.8$ & $110.4 \pm 12.4$ & - & $111.5 \pm 18.9$ & - & $107.7 \pm 17.7$ & - & n.s. ${ }^{\&}$ \\
\hline Diastolic BP, mmHg & $73.1 \pm 9.6$ & $71.5 \pm 10.4$ & - & $72.8 \pm 14.1$ & - & $69.9 \pm 15.6$ & - & n.s. ${ }^{\&}$ \\
\hline Stroke volume index, $\mathrm{mL} / \mathrm{m}^{2}$ & $37.5 \pm 10.8$ & $37.6 \pm 9.5$ & - & $37.0 \pm 9.3$ & - & $36.9 \pm 9.0$ & - & n.s. ${ }^{\&}$ \\
\hline Cardiac index, $\mathrm{L} / \mathrm{min} / \mathrm{m}^{2}$ & $2.5 \pm 0.7$ & $2.5 \pm 0.6$ & - & $2.4 \pm 0.5$ & - & $2.4 \pm 0.5$ & - & n.s. ${ }^{\&}$ \\
\hline TPRI, dyne $\cdot \mathrm{s} \mathrm{m}^{2} \mathrm{~cm}^{-5}$ & $3006.4 \pm 978.8$ & $2932.8 \pm 929.1$ & - & $3027.5 \pm 886.6$ & - & $2918.3 \pm 907.7$ & - & n.s. ${ }^{\&}$ \\
\hline
\end{tabular}

Values are depicted as mean and standard deviation or median (interquartile range) for sleep segment of 10-min duration taken from stable N2 sleep with sinus rhythm. Post hoc $t$ tests were not performed when results of multigroup comparisons were non-significant

$N H F$ nasal high flow, $N I V$ non-invasive ventilation, $B R S$ slope slope of baroreceptor reflex sensitivity (up events and down events), $H F n u d B P V$ highfrequency component of diastolic blood pressure variability, $H F n u R R I$ high-frequency component of heart rate variability, $L F n u d B P V$ low-frequency component of diastolic blood pressure variability, $L F / H F d B P V$ relative ratio of low-frequency and high-frequency component of diastolic blood pressure variability, $L F n u R R I$ low-frequency component of heart rate variability, $L F / H F R R I$ relative ratio of low-frequency and high-frequency component of heart rate variability, $n u$ normalised units (normalised for total power spectra), n.s. not statistically significant, TPRI total peripheral resistance index

${ }^{1)} p$ values for comparison with baseline values ("no treatment") using the paired test

2) $p$ values for comparison between all groups/variables

${ }^{\&}$ Univariate ANOVA

alone. Combination of NHF with $\mathrm{O}_{2}$ supplementation may predominantly account for improved oxygenation and reduction of respiratory rate which both have been reported in adult patients with acute respiratory failure and COPD. In children, low positive airway pressure levels as achievable by NHF may be sufficient to meaningfully reduce obstructive events [36-40].

\section{Tolerability of NHF50}

Application of NHF50 was poorly tolerated by patients with NMD in the present study. Tolerability was low both in the awake state during daytime and during nocturnal sleep. This finding seems to contradict previous studies that showed improvement of subjective well-being by NHF oxygen therapy with higher flow rates in patients with COPD, NMD or heart failure $[14,16,18,22,41]$. Two aspects may help explain these discrepant findings. First, beneficial effects of NHF were previously made in patients with acute dyspnea or in patients declining NIV therapy. In contrast, tolerability of NHF50 may obviously be hampered in non-dyspneic patients who mainly experience significant discomfort due to noise and nasal flow sensation. Second, improved oxygenation is likely perceived as directly relieving by patients with COPD or heart failure in whom hypoxic respiratory failure is also present. In particular, correction of hypoxia lowers sympathetic drive and reduces respiratory rate both leading to more efficient ventilation and clearance of $\mathrm{CO}_{2}$. 


\section{Impact of NHF or NIV on sympathovagal balance}

In this study, it could not be confirmed that application of either NHF or NIV translates into a decrease in sympathetic drive. Neutral effects of NHF on autonomous nervous system activity may simply be explained by the fact that SDB was not significantly alleviated. Furthermore, study participants showed sleep disruption - especially with NHF 50-which may have negated any positive effects on SVB.

With regard to the effects of nocturnal NIV on autonomous nervous system activity this study could not show any robust improvement although both hypoventilation and hypercapnia during sleep were adequately treated. However, study participants were already used to NIV before which might have been associated with better tolerability of this intervention in this study.

The results of this study suggest that patients with NMD and mild to moderate $\mathrm{NH}$ do not represent appropriate candidates for NHF. First, these patients usually do not present with hypoxia and acute or chronic dyspnea which are linked to increased sympathetic nerve activity. Second, these patients do not show a rapid shallow breathing pattern whose correction by NHF translates into reduced work of breathing and hence sympathetic drive.

\section{Study limitations}

The present study has several limitations that have to be taken into account. Firstly, the number of patients enrolled was too small to statistically deduce evidence which can reliably be generalised. However, this study aimed to provide (or falsify) a first-ever proof of principle regarding the use of NHF in NMD patients with NH. Secondly, duration of each intervention was a priori limited to about $2 \mathrm{~h}$. It cannot be excluded that longer periods of NHF would have exerted different effects on the variables evaluated in this study. Thirdly, sympathetic drive was not measured invasively, e.g. by direct recording of muscle sympathetic nerve activity. Non-invasive recording of HRV and $\mathrm{dBPV}$ can only provide an overall estimate of SVB, including also the vagal component. However, close correlation between muscle sympathetic nerve activity and $\mathrm{HRV} / \mathrm{dBPV}$ measures (LF/HF ratios in particular) has previously been shown $[42,43]$.

Finally, tolerability of NHF was potentially hampered by the fact that patients were confronted with this kind of ventilatory support for the first time. At the same time, low tolerability of NHF50 in particular is in line with one recent previous report on this in adult patients with obstructive sleep apnoea [44]. In contrast, all patients had started NIV substantially earlier including the opportunity to get used to it. In order to account for this assumption, we thoroughly introduced NHF to study participants prior to the daytime recordings. However, study results may be limited with regard to sleep quality measures and SVB parameters, in particular.

\section{Conclusion}

The present study speaks out against the use of NHF as a treatment alternative to NIV in non-dyspneic NMD patients with mild to moderate NH or obstructive sleep apnea. NHF appears to be less tolerable than bi-level ventilatory support for patients with previously established NIV. Conventional NIV sufficiently corrects sleep-related hypercapnia in these patients without adverse effects on sleep or sympathetic drive.

Acknowledgements We gratefully acknowledge Mr. Christian Glatz's and Mr. Salvador Perez's kind technical help in collecting our data, Dr. Tobias Brix's help in editing tables and Dr. Jürgen Fortin's help in analysing and interpreting autonomic nervous system, SVB and haemodynamic data. English language editing assistance was provided by Nicola Ryan, an independent medical writer.

Author contributions JS, MB, AB and HS designed the study. AM, NS, $\mathrm{AH}$ and $\mathrm{CT}$ were responsible for data collection. JS, AM and TB performed the statistical analyses, and JS, AM, MB and MD prepared the manuscript which was critically revised and amended by $\mathrm{AB}, \mathrm{PY}, \mathrm{AH}$ and MD.

Funding Open Access funding enabled and organized by Projekt DEAL. This study was supported Löwenstein Medical. The funders had no role in study design, data collection, data analysis or preparation of the manuscript.

\section{Compliance with ethical standards}

Conflict of interest JS is supported by the Else-Kröner-Fresenius Stiftung (Grant SP A109) for this work, and by Kommission für Innovative Medizinische Forschung an der Medizinischen Fakultät Muenster (IMF Grant SP 1118 15), by Deutsche Herzstiftung (DHS Grant S/01/19) and by young investigator research support from Scuola Superiore Sant'Anna Pisa (Curriculum Ph.D. in Translational Medicine) and has received travel grants and lecture honoraria from Boehringer Ingelheim and Chiesi (all) outside the present work. MB is supported by Sanofi Genzyme outside this work. MB and PY have received speaker honoraria and travel grants from Sanofi Genzyme and Löwenstein Medical. MD reports to have received travel grants and/or speaking fees and/or fees for consulting from Actelion, Astra Zeneca, Bayer, Berlin Chemie, Boehringer, Chiesi, Hamilton, Heinen und Löwenstein, Intermune, Linde, Novartis, Pfizer, Philips Respironics, ResMed, Roche and Weinmann. AM, CT, NS, HS, AH and AB declare no conflicts of interest in the context of this paper.

Statement of ethics The study protocol has been approved by the research institute's committee on human research. Subjects have given their written informed consent.

Open Access This article is licensed under a Creative Commons Attribution 4.0 International License, which permits use, sharing, adaptation, distribution and reproduction in any medium or format, as long as you give appropriate credit to the original author(s) and the source, provide a link to the Creative Commons licence, and indicate if changes were made. The images or other third party material in this article are included in the article's Creative Commons licence, unless indicated otherwise in a credit line to the material. If material is not included in the article's Creative Commons licence and your intended use is not permitted by statutory regulation or exceeds the permitted use, you will need to obtain 
permission directly from the copyright holder. To view a copy of this licence, visit http://creativecommons.org/licenses/by/4.0/.

\section{References}

1. Boentert M, Wenninger S, Sansone VA (2017) Respiratory involvement in neuromuscular disorders. Curr Opin Neurol 30(5): 529-537

2. Benditt JO (2002) Respiratory complications of amyotrophic lateral sclerosis. Semin Respir Crit Care Med 23(3):239-247

3. D'Cruz RF, Murphy PB, Kaltsakas G (2018) Sleep disordered breathing in motor neurone disease. J Thorac Dis 10(Suppl 1): S86-S93

4. Boentert M, Karabul N, Wenninger S, Stubbe-Dräger B, Mengel E, Schoser B, Young P (2015) Sleep-related symptoms and sleepdisordered breathing in adult Pompe disease. Eur J Neurol 22(2): 369-376 e27

5. Laberge L, Bégin P, Dauvilliers $Y$, Beaudry M, Laforte M, Jean S et al (2009) A polysomnographic study of daytime sleepiness in myotonic dystrophy type 1 . J Neurol Neurosurg Psychiatry 80(6): 642-646

6. Henke C, Spiesshoefer J, Kabitz H-J, Herkenrath S, Randerath W, Brix T, Görlich D, Young P, Boentert M (2019) Respiratory muscle weakness in facioscapulohumeral muscular dystrophy. Muscle Nerve 60(6):679-686

7. Spiesshoefer J, Henke C, Kabitz HJ, Brix T, Görlich D, Herkenrath S, Randerath W, Young P, Boentert M (2019) The nature of respiratory muscle weakness in patients with late-onset Pompe disease. Neuromuscul Disord 29(8):618-627

8. Runte M, Spiesshoefer J, Heidbreder A, Dreher M, Young P, Brix $\mathrm{T}$, Boentert M (2019) Sleep-related breathing disorders in facioscapulohumeral dystrophy. Sleep Breath 23(3):899-906

9. Spiesshoefer J, Runte M, Heidbreder A, Dreher M, Young P, Brix T, Boentert M (2019) Sleep-disordered breathing and effects of non-invasive ventilation on objective sleep and nocturnal respiration in patients with myotonic dystrophy type I. Neuromuscul Disord 29(4):302-309

10. Berger KI, Rapoport DM, Ayappa I, Goldring RM (2014) Pathophysiology of hypoventilation during sleep. Sleep Med Clin 9(3):289-300

11. Windisch W, Geiseler J, Simon K, Walterspacher S, Dreher M (2018) German National Guideline for treating chronic respiratory failure with invasive and non-invasive ventilation: revised edition 2017 - part 1. Respiration 96(1):66-97

12. O'Donoghue FJ, Borel J-C, Dauvilliers Y, Levy P, Tamisier R, Pépin J-L (2017) Effects of 1-month withdrawal of ventilatory support in hypercapnic myotonic dystrophy type 1. Respirology 22(7): 1416-1422

13. Boussaïd G, Lofaso F, Santos DB, Vaugier I, Pottier S, Prigent H, Orlikowski D, Bahrami S (2016) Factors influencing compliance with non-invasive ventilation at long-term in patients with myotonic dystrophy type 1: a prospective cohort. Neuromuscul Disord 26(10):666-674

14. Millar J, Lutton S, O'Connor P (2014) The use of high-flow nasal oxygen therapy in the management of hypercarbic respiratory failure. Ther Adv Respir Dis 8(2):63-64

15. Biselli PJC, Kirkness JP, Grote L, Fricke K, Schwartz AR, Smith P, Schneider H (2017) Nasal high-flow therapy reduces work of breathing compared with oxygen during sleep in COPD and smoking controls: a prospective observational study. J Appl Physiol 122(1):82-88
16. Bräunlich J, Köhler M, Wirtz H (2016) Nasal highflow improves ventilation in patients with COPD. Int J Chron Obstruct Pulmon Dis 11:1077-1085

17. Bräunlich J, Seyfarth H-J, Wirtz H (2015) Nasal high-flow versus non-invasive ventilation in stable hypercapnic COPD: a preliminary report. Multidiscip Respir Med 10(1):27

18. Bräunlich J, Wirtz H (2017) NHF and hypercapnia: how brief can you look? Respirology 22(6):1049-1050

19. Groves N, Tobin A (2007) High flow nasal oxygen generates positive airway pressure in adult volunteers. Aust Crit Care 20(4):126131

20. de Jongh BE, Locke R, Mackley A, Emberger J, Bostick D, Stefano J, Rodriguez E, Shaffer TH (2014) Work of breathing indices in infants with respiratory insufficiency receiving high-flow nasal cannula and nasal continuous positive airway pressure. J Perinatol 34(1):27-32

21. Möller W, Feng S, Domanski U, Franke K-J, Celik G, Bartenstein P, Becker S, Meyer G, Schmid O, Eickelberg O, Tatkov S, Nilius G (2017) Nasal high flow reduces dead space. J Appl Physiol 122(1): 191-197

22. Díaz-Lobato S, Folgado MA, Chapa A, Mayoralas AS (2013) Efficacy of high-flow oxygen by nasal cannula with active humidification in a patient with acute respiratory failure of neuromuscular origin. Respir Care 58(12):e164-e167

23. Bartsch T, Häbler HJ, Jänig W (1999) Hypoventilation recruits preganglionic sympathetic fibers with inspiration-related activity in the superior cervical trunk of the rat. J Auton Nerv Syst 77(1): $31-38$

24. Macefield VG, Wallin BG (1999) Respiratory and cardiac modulation of single sympathetic vasoconstrictor and sudomotor neurones to human skin. J Physiol Lond 516(Pt 1):303-314

25. Ogna A, Quera Salva M-A, Prigent H, Mroue G, Vaugier I, Annane D, Lofaso F, Orlikowski D (2016) Nocturnal hypoventilation in neuromuscular disease: prevalence according to different definitions issued from the literature. Sleep Breath 20(2):575-581

26. Berry RB, Budhiraja R, Gottlieb DJ, Gozal D, Iber C, Kapur VK, Marcus CL, Mehra R, Parthasarathy S, Quan SF, Redline S, Strohl KP, Davidson Ward SL, Tangredi MM, American Academy of Sleep Medicine (2012) Rules for scoring respiratory events in sleep: update of the 2007 AASM manual for the scoring of sleep and associated events. J Clin Sleep Med 08(05):597-619

27. Fortin J, Habenbacher W, Heller A, Hacker A, Grüllenberger R, Innerhofer J, Passath $\mathrm{H}$, Wagner C, Haitchi G, Flotzinger D, Pacher R, Wach P (2006) Non-invasive beat-to-beat cardiac output monitoring by an improved method of transthoracic bioimpedance measurement. Comput Biol Med 36(11):1185-1203

28. Fortin J, Marte W, Grüllenberger R, Hacker A, Habenbacher W, Heller A, Wagner CH, Wach P, Skrabal F (2006) Continuous noninvasive blood pressure monitoring using concentrically interlocking control loops. Comput Biol Med 36(9):941-957

29. Gratze G, Fortin J, Holler A, Grasenick K, Pfurtscheller G, Wach P, Schönegger J, Kotanko P, Skrabal F (1998) A software package for non-invasive, real-time beat-to-beat monitoring of stroke volume, blood pressure, total peripheral resistance and for assessment of autonomic function. Comput Biol Med 28(2):121-142

30. Karemaker JM (2017) An introduction into autonomic nervous function. Physiol Meas 38(5):R89-R118

31. Pagani M, Montano N, Porta A, Malliani A, Abboud FM, Birkett C, Somers VK (1997) Relationship between spectral components of cardiovascular variabilities and direct measures of muscle sympathetic nerve activity in humans. Circulation 95(6):1441-1448

32. Mirizzi G, Giannoni A, Bramanti F, Ripoli A, Varanini M, Bernardi L, Emdin M, Passino C (2013) A simple method for measuring baroreflex sensitivity holds prognostic value in heart failure. Int $\mathrm{J}$ Cardiol 169(1):e9-e11 
33. Mündel T, Feng S, Tatkov S, Schneider H (2013) Mechanisms of nasal high flow on ventilation during wakefulness and sleep. J Appl Physiol 114(8):1058-1065

34. Bräunlich J, Beyer D, Mai D, Hammerschmidt S, Seyfarth H-J, Wirtz H (2013) Effects of nasal high flow on ventilation in volunteers, COPD and idiopathic pulmonary fibrosis patients. Respiration 85(4):319-325

35. Sztrymf B, Messika J, Mayot T, Lenglet H, Dreyfuss D, Ricard J-D (2012) Impact of high-flow nasal cannula oxygen therapy on intensive care unit patients with acute respiratory failure: a prospective observational study. J Crit Care 27(3):324.e9-324.13

36. Amaddeo A, Khirani S, Frapin A, Teng T, Griffon L, Fauroux B (2019) High-flow nasal cannula for children not compliant with continuous positive airway pressure. Sleep Med 63:24-28

37. Luo J, Duke T, Chisti MJ, Kepreotes E, Kalinowski V, Li J (2019) Efficacy of high-flow nasal cannula vs standard oxygen therapy or nasal continuous positive airway pressure in children with respiratory distress: a meta-analysis. J Pediatr 215:199-208.e8

38. Fagan EA, Ellis DS, Portmann B, Tovey GM, Williams R, Zuckerman AJ (1987) Microbial structures in a patient with sporadic non-a, non-B fulminant hepatitis treated by liver transplantation. J Med Virol 22(2):189-198

39. Ejiofor BD, Carroll RW, Bortcosh W, Kacmarek RM (2019) PEEP generated by high-flow nasal cannula in a pediatric model. Respir Care 64(10):1240-1249
40. Lodeserto FJ, Lettich TM, Rezaie SR (2018) High-flow nasal cannula: mechanisms of action and adult and pediatric indications. Cureus 10(11):e3639

41. Bräunlich J, Dellweg D, Bastian A, Budweiser S, Randerath W, Triché D, Bachmann M, Kähler C, Bayarassou AH, Mäder I, Geiseler J, Köhler N, Petroff D, Wirtz H (2019) Nasal high-flow versus noninvasive ventilation in patients with chronic hypercapnic COPD. Int J Chron Obstruct Pulmon Dis 14:1411-1421

42. van de Borne P, Montano N, Zimmerman B, Pagani M, Somers VK (1997) Relationship between repeated measures of hemodynamics, muscle sympathetic nerve activity, and their spectral oscillations. Circulation 96(12):4326-4332

43. Kienzle MG, Ferguson DW, Birkett CL, Myers GA, Berg WJ, Mariano DJ (1992) Clinical, hemodynamic and sympathetic neural correlates of heart rate variability in congestive heart failure. Am J Cardiol 69(8):761-767

44. Ho CH, Chen CL, Yu CC, Yang YH, Chen CY (2020) High-flow nasal cannula ventilation therapy for obstructive sleep apnea in ischemic stroke patients requiring nasogastric tube feeding: a preliminary study. Sci Rep 10(1):8524

Publisher's note Springer Nature remains neutral with regard to jurisdictional claims in published maps and institutional affiliations. 